\title{
La búsqueda local sustituye a la guía telefónica clásica
}

\author{
Por Toon Lowette
}

\begin{abstract}
Resumen: Los editores de páginas amarillas y de directorios de empresas sienten la fuerte competencia de internet y se ven obligados a buscar nuevas vías de ingresos refugiándose en los mercados locales, en publicidad y en servicios más personalizados a sus usuarios.

Palabras clave: Directorios de empresas, Páginas amarillas, Crisis económica, Nuevos mercados, Asesoramiento a los usuarios, Publicidad.

Title: Local search replaces the classic telephone directory

Abstract: The publishers of yellow pages and business directories are suffering strong competition from the internet and are forced to seek new ways of income, taking refuge in local markets and more personalized services to their users.

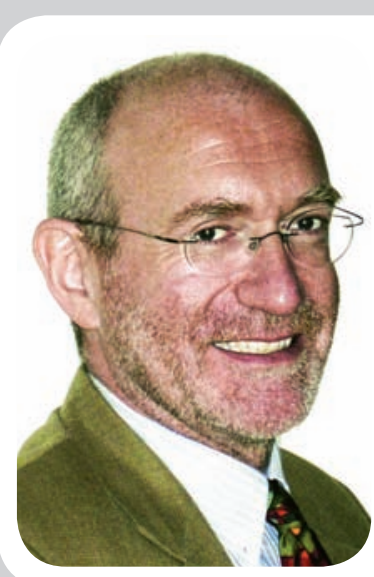

Toon Lowette comenzó a trabajar en la edición electrónica y los servicios interactivos en 1982. Ha dirigido proyectos, puesto en marcha empresas, asesorado a la Comisión Europea, a operadores de telecomunicaciones, bancos y otras empresas, así como a organizaciones profesionales como la EADP. Ha publicado numerosos informes del mercado y la industria de las bases de datos y del sector editorial.
\end{abstract}

Keywords: Business directories, Yellow pages, Economic crisis, New markets, Assessment to users, Advertising.

Lowette, Toon. "La búsqueda local sustituye a la guía telefónica clásica”. El profesional de la información, 2009, julioagosto, v. 18, n. 4, pp. 424-426.

DOI: $10.3145 /$ epi.2009.jul.10

LOS EDITORES DE DIRECTORIOS de empresas, páginas amarillas, etc., parecen sentir plenamente los efectos de la transición del papel a los medios electrónicos.

Y la situación no les resulta fácil. Algunos incluso se preguntan si pueden seguir siendo editores. La organización europea en la que están asociados, European Association of Directory and Database Publishers (EADP), celebró su conferencia de primavera en Barcelona -por tercer año consecutivo- los días 28-29 de mayo de 2009.

El tema general de la conferencia reflejaba los signos económicos de los tiempos: "Performance, performance, performance" (esa palabra de difícil traducción al español que significa eficiencia, rendimiento, ejecución, desempeño, resultados...).

Los miembros de la EADP son principalmente editores de páginas amarillas y de directorios de empresas. Éstos últimos, los directo- rios de productos y servicios empresa-a-empresa, ya no se publican en papel, y casi el $100 \%$ de los ingresos de sus editores les llegan de internet. En el área de páginas amarillas por el contrario, la mayoría de los ingresos y el (descenso de) los beneficios proceden todavía de un sinnúmero de guías telefónicas en páginas blancas y amarillas. En promedio, la parte de ingresos online sólo es de alrededor del $25 \%$.

\section{"La abrumadora competencia de internet obliga a los editores a buscar nuevas vías de ingresos"}

\section{Pasaron las vacas gordas}

Pero los márgenes se hacen más y más pequeños, y los ingresos por el papel disminuyen. La mayoría de los editores perdieron del 10 al 15\% del volumen de negocios en 2008, y ello reforzó fuertemente la tendencia a la baja de los últimos cinco años, que venía siendo más suave.

Centrar la conferencia en el rendimiento, por lo tanto, era lógico. Los accionistas demandan crecimiento y más beneficios (en la actualidad la mayoría de ellos son sociedades de inversión o el público en general a través de acciones de bolsa, ya que muy pocas guías telefónicas siguen siendo editadas por operadoras de telecomunicaciones).

El tema del rendimiento (y obviamente, de la rentabilidad) se trató ampliamente en la conferencia, en las diferentes facetas del negocio: cómo obtener buenos contenidos, por ejemplo. Cómo producir bases de datos con información de contacto de calidad (mantener actualizada una base de datos de teléfonos y contactos requiere grandes esfuerzos en tecnologías de la información y en personal de mantenimiento) y que se complemente con el contenido generado por el usuario, con mapas en $2 \mathrm{D}$ o $3 \mathrm{D}$, 


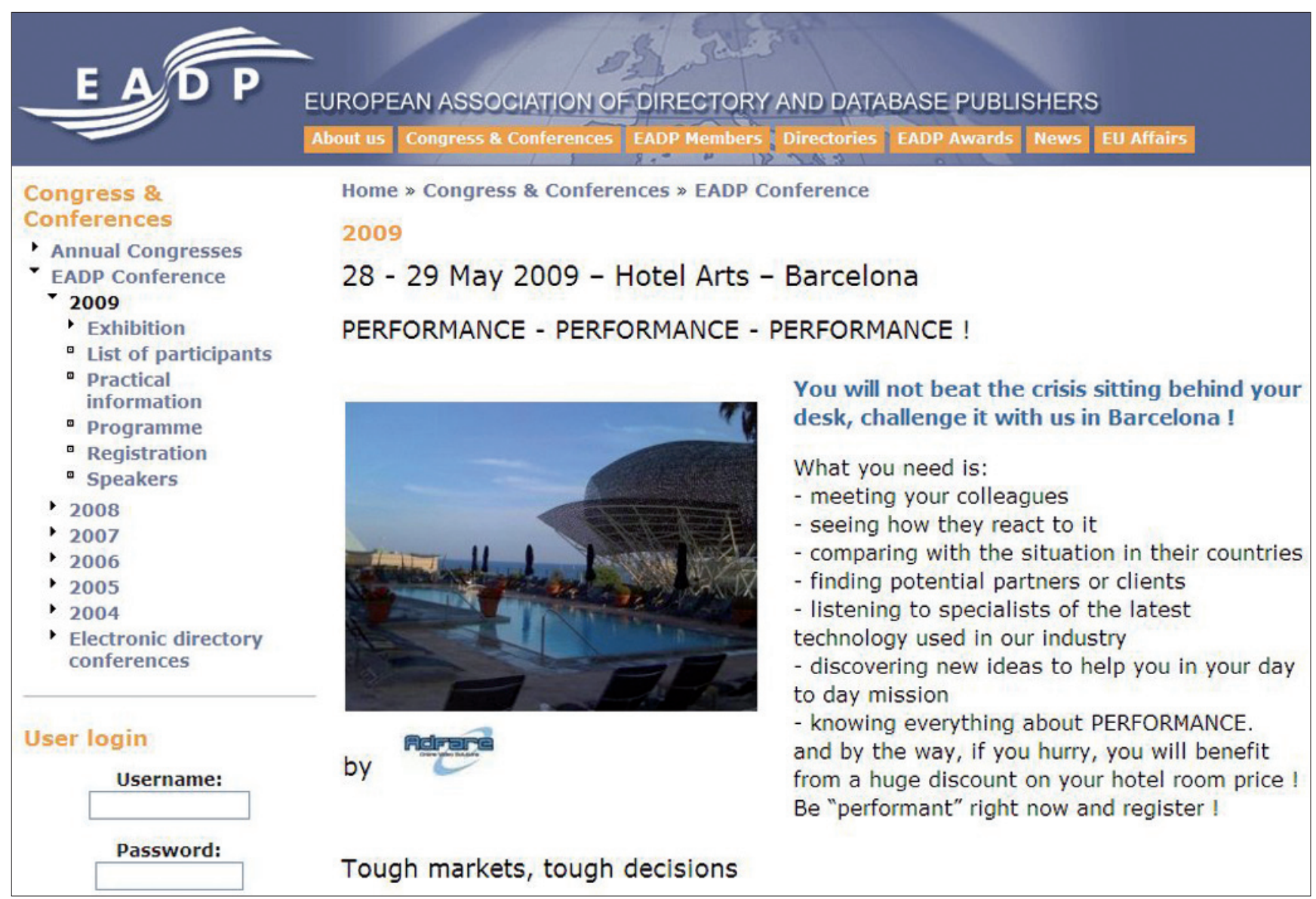

La conferencia de Barcelona anunciada en la web de la EADP

revisiones, valoraciones, y todas las nuevas formas de integración (mash-ups) de contenidos extraídos de varias fuentes.

\section{Reorientación del negocio}

De todas maneras, aunque los editores de directorios son productores de bases de datos, en la práctica su negocio se centra básicamente en la venta de publicidad. Sus ingresos provienen del hecho de que comerciantes y empresas quieran ser encontrados por un público que les busca.

Las búsquedas se hacen cada vez más online, a través de la web o de dispositivos móviles como los teléfonos inteligentes (smartphones). Las webs de páginas amarillas tienen éxito y crece su número de visitantes, ya que su relevancia se comprueba fácilmente tanto por la satisfacción de los usuarios como por los ingresos de los editores, pero estos ingresos no son suficien- tes para compensar las pérdidas de los directorios en papel.

En las conferencias $E A D P$ a la "publicación de directorios" se la llama cada vez más "publicación de búsqueda local”. Ahí está el punto fuerte de esos editores en comparación con Google, su principal competidor. Por cierto, muchos editores de directorios colaboran con Google con el fin de combinar las fortalezas de ambos: búsqueda general y búsqueda local.

\section{"Para escapar de Google los editores se dedican a personalizar y fidelizar los mercados locales"}

Y luego están Twitter y Facebook y las demás redes sociales nuevas donde las personas consultan a sus amigos por un fontanero, un distribuidor de alfombras o un restaurante en lugar de recurrir a un directorio. Por lo tanto, los editores tienen que encontrar formas de estar presentes en estas redes, y eso no es tarea fácil porque a menudo sus miembros no quieren hacer caso a ninguna forma de publicidad. En resumen, tienen que buscar nuevas asociaciones que les sean rentables.

Por tanto, las ventas de los editores tienen que ser también más eficientes. El desafío de monetizar sus bases de datos nunca había sido tan grande. Están muy lejos ahora de la situación de monopolio que disfrutaron hasta la década de 1990 cuando un editor podría rastrillar el dinero de los anunciantes sin competencia y sin tener que justificar las cifras de uso como ahora.

\section{De editores a agencias de publicidad}

Algunos sacan conclusiones y cambian su estrategia de forma bastante radical. Truvo, editor de pági- 
nas amarillas muy activo en Bélgica, Portugal, Irlanda y Rumanía, ha empezado a llamarse algo así como "organización de venta de publicidad en búsquedas locales". Sigue siendo claramente un editor de bases de datos, pero cede el eje central de la empresa al departamento de ventas de publicidad. Este re-enfoque fue una novedad en la conferencia $E A D P$.

Golden Pages de Israel, por otra parte, aunque tiene mucho éxito con más del $60 \%$ de sus ingresos procedentes de internet, siente tan fuerte la presión por parte de Google que ha reorientado su actividad principal a asesorar a los comerciantes y las pequeñas y medianas empresas que deseen invertir en publicidad cualquier presupuesto, tanto por televisión, radio, revistas, carteles o folletos. Según la empresa, esa es un área en la que no van a toparse con Google. Golden Pages tienen la ambición de convertirse en la agencia de publicidad más grande de Israel. Un plan estratégico que sorprendió a más de un participante en la conferencia de Barcelona.

\section{"Además de proveer información, algunos editores de directorios tienen que ponerse a asesorar a sus usuarios"}

Esto nos lleva a una extraña constatación. Antes de internet, el único contenido de las guías telefónicas eran listas de números telefónicos y publicidad, pero aun así las empresas se llamaban a sí mismas "editores". En la actualidad siguen teniendo esas bases de datos de números de teléfono y además mucha más información, a partir de la cual publican directorios, sitios web, servicios para móviles y smartphones, están presentes en dispositivos de navegación de automóviles y actualizan directorios de las intranets corporativas, y son más editores que nunca. Sin embargo ahora la competencia, el bajo rendimiento económico y el cada vez más exigente usuario de búsqueda local les lleva a reconsiderar la esencia de sus actividades de publicación.

Una cosa saben con seguridad: la necesidad de búsqueda local y servicios de información basados en localización continúa aumentando fuertemente. La única duda es si este hambre de información sabrán saciarlo ellos.

La conferencia de primavera EADP 2010 tendrá lugar en Palma de Mallorca

http://www.eadp.org

Toon Lowette, GRID, Electronic Publishing Consultancy. Lakensestraat, 147 b 15, B-1000 Brussels. toon@grid.be

http://www.grid.be

\section{Si te interesan los}

\section{NDICADORES EN CIENGIA TECNOLOGÍA,}

\section{y todos los temas relacionados conta merthiole le clencia, tales como:}

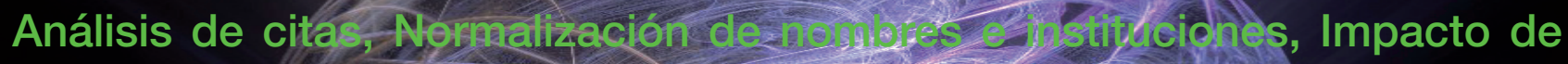

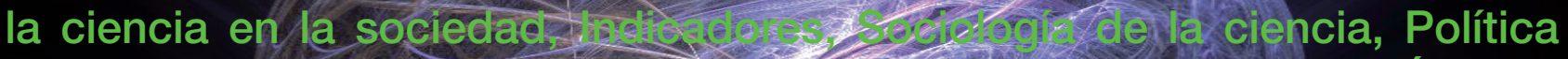
científica, Comunicación de tarminis? Bases de datos, Índices de impacto, Políticas de oper ace -ss, filisis de la nueva economía, Mujer y ciencia, etc.

\section{Entonces INCY es tu lista. Suscribete en:}

\section{http://www.rediris.es/list/info/incyt.htmI}

